This item was submitted to Loughborough's Research Repository by the author.

Items in Figshare are protected by copyright, with all rights reserved, unless otherwise indicated.

\title{
Quality of life and building design in residential and nursing homes for older people
}

PLEASE CITE THE PUBLISHED VERSION

PUBLISHER

(c) Cambridge University Press

LICENCE

CC BY-NC-ND 4.0

\section{REPOSITORY RECORD}

Parker, Chris, Sarah Barnes, Kevin McKee, Kevin Morgan, Judith Torrington, and Peter Tregenza. 2019. "Quality of Life and Building Design in Residential and Nursing Homes for Older People". figshare. https://hdl.handle.net/2134/2222. 
This item was submitted to Loughborough's Institutional Repository by the author and is made available under the following Creative Commons Licence conditions.

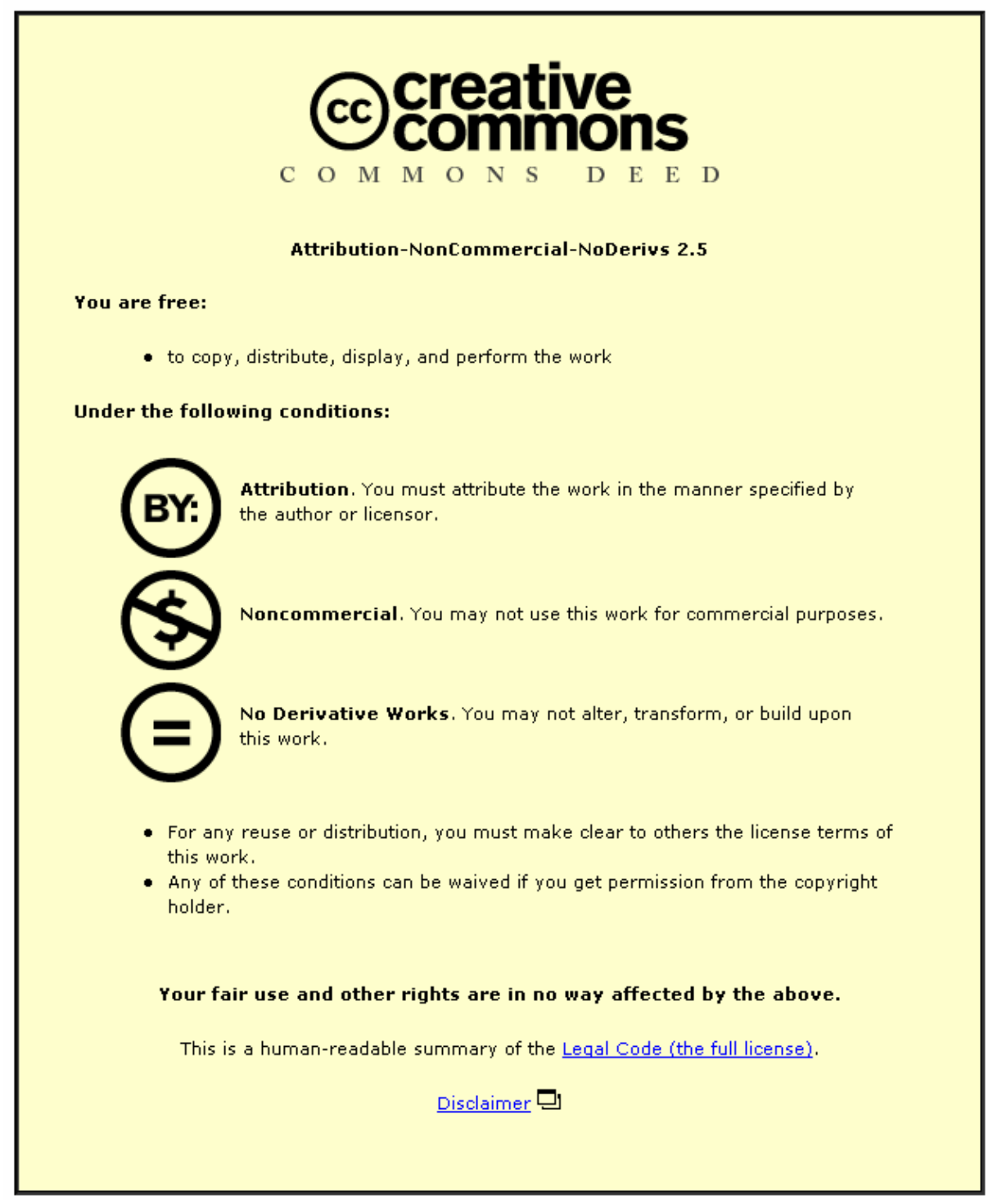

For the full text of this licence, please go to: http://creativecommons.org/licenses/by-nc-nd/2.5/ 


\title{
Quality of life and building design in resi- dential and nursing homes for older people
}

\author{
CHRIS PARKER*, SARAH BARNES*, KEVIN MCKEE*, \\ KEVIN MORGAN†, JUDITH TORRINGTON** \\ and PETER TREGENZA**
}

\begin{abstract}
Older people living in residential and nursing care homes spend a large proportion of their time within the boundaries of the home, and may depend on the environment to compensate for their physical or cognitive frailties. Regulations and guidelines on the design of care buildings have accumulated over time with little knowledge of their impact on the quality of life of building users. The Design in Caring Environments Study (DICE) collected cross-sectional data on building design and quality of life in 38 care homes in and near Sheffield, Yorkshire. Quality of life was assessed using methods which included all residents regardless of their frailty, and staff morale was also assessed. The physical environment was measured on II user-related domains using a new tool, the Sheffield Care Environment Assessment Matrix (SCEAM). Significant positive associations were found between several aspects of the built environment and the residents' quality of life. There was evidence that a focus on safety and health requirements could be creating risk-averse environments which act against quality of life, particularly for the least frail residents. Staff morale was associated with attributes of a noninstitutional environment for residents rather than with the facilities provided for the staff. The new tool for assessing building design has potential applications in further research and for care providers.
\end{abstract}

KEY WORDS - quality of life, environment, building design, care home.

\section{Introduction}

The physical environment in which we live is a recognised dimension of the quality of life (World Health Organisation Quality of Life Assessment (WHOQOL) Group I998), and is likely to be particularly important for older people living in residential or nursing care settings. Many spend the vast majority of their time within the boundaries of the home (Kellaher

* Sheffield Institute for Studies on Ageing, University of Sheffield.

$\dagger$ Department of Human Sciences, Loughborough University.

** School of Architecture, University of Sheffield. 
I986), and depend on the environment to compensate for impaired mobility, sensory losses or the cognitive impairments associated with dementia (Brawley 200I). The design of care buildings is therefore of crucial importance to this large number of older people: it has been the focus of the Design in Caring Environments Study (DICE), the main findings of which are reported in this paper.

In the United Kingdom, regulations for care buildings were until recently set by individual local government and National Health Service Health Authorities, and they varied across the country. Now, however, a uniform set of criteria administered by the National Care Standards Commission apply (Department of Health 2001 a). Standards for the environment focus principally on the physical needs of residents, covering such requirements as size of rooms, accessibility, facilities, furniture and fittings. Psychological needs such as privacy and dignity are dealt with as care issues, rather than as building features which promote or facilitate them. There is little guidance on the environmental needs of people with dementia, who constitute a large proportion of the residents in British institutional care settings. The standards represent the current state of an incremental upgrading process which has had little input from research (Barnes 2002).

In the architecture and design professions, it is rare for academic curricula to cover the needs of frail older people. Guidelines exist for specialist professionals (e.g. Torrington I996; Judd et al. I998), but like the regulations these have been developed with little input from research involving building users. The residents' building preferences as inferred by designers have been shown to be very different from those that are actually held (Duffy et al. 1986). There is little evaluation of new buildings once they have been occupied, with a consequent lack of feedback to professionals on how design features work in practice.

The development of research on building design is however problematic. Observational studies can explore relationships but cannot establish cause and effect, although this is often claimed. The interaction of the individual with the physical environment occurs in diverse organisational and social contexts, making it difficult to unpick genuine associations (Calkins 200I). For example, the quality of life of residents may be strongly related to the quality of the care provided, but this in turn may be related to the physical environment (Gilloran et al. I995). Moos and Lemke (I980) found that staff with better facilities provided residents with more choice in their daily activities and more influence on a home's policies. There is a danger of 'controlling out' genuine effects of the environment if they operate through a care-culture effect (Netten i989). Longitudinal research designs can relate changes in the quality of life over time to the physical environment, as by testing hypotheses that a better environment will at least 
maintain and possibly improve such indicators as wellbeing and cognitive state. In practice, the study of the longitudinal effects of design changes is made difficult by the high mortality rate among the frailest residents (Netten 1993). Large experimental studies would provide the strongest evidence, but are impossible in this context because they require the random allocation of people to buildings. The scope for experimentation is limited to the effects of minor environmental changes, and most studies focus on residents with dementia. The findings often relate strongly to the individual setting and are difficult to generalise into overall design guidance. For example, marking a line across the floor near a doorway has been found in different studies to reduce unauthorised exiting, to increase it, and to make no difference (Calkins 200I).

Research is also limited by a lack of suitable measures. For the physical environment, most assessment tools are specific to dementia care, and none cover all the features of British care settings (Barnes 2002). A measure of quality of life is needed as a criterion: any measure which relies on selfreport from residents will exclude the frailest, particularly those with significant cognitive impairments. A typical finding from a study of residents' opinions of nursing homes was that more than half were unable to respond because of cognitive impairment, sensory loss or illness (Higgs et al. I998). Those who are able to report a level of satisfaction tend to give uniformly positive responses and to avoid being critical (Pearson et al. 1993). This paper reports the key findings of the DICE study, which investigated relationships between the physical environment and quality of life in long term care settings for older people, and describes the development of a new environmental assessment tool, the Sheffield Care Environment Assessment Matrix (SCEAM).

\section{Methods}

\section{The sample}

The 120 residential and nursing homes registered in Sheffield in May 2000 were stratified into three approximately equal groups based on the number of beds: small (less than 3I), medium (3I-40) and large (4I or more). Architecturally and functionally the three groups were very distinct. Small homes were all privately run and almost all were residential care homes. They were characterised by a hotel layout: all residents used all public spaces and facilities throughout the building. They included conversions of Victorian or Edwardian houses with large reception rooms, high quality fittings and fixtures and mature gardens: there were also some newer purpose-built homes. Medium sized homes were residential care homes, 
purpose-built by the local authority, with generous public spaces but generally small bedrooms. They had group-living layouts: clusters of the residents' private rooms each with their own communal lounges, dining rooms and bathrooms, with the residents also able to use spaces and facilities throughout the building. Large homes were private nursing or residential care and nursing homes (customarily known as dual-registered homes), and all were purpose-built. Room areas, facilities and safety standards were comparatively high. Most comprised several independent living units: groups of residents' rooms occupied discrete wings, and residents had little or no access to other units. One or more units were usually for 'elderly mentally infirm' (EMI) residents.

Equal numbers of buildings were recruited in each group to represent the range of care settings in the area. Within each group, homes were contacted in random order until enough had been recruited. As a low consent rate was achieved among small homes, the io registered care homes of fewer than $3 \mathrm{I}$ beds in the neighbouring town of Rotherham were subsequently added to the sampling frame, making a total of I3o buildings.

Sample size estimation indicated that 147 individual residents would be required to detect a moderate effect on one of the proposed measures of quality of life, with a significance level of five per cent and a power of 80 per cent. It was necessary to increase the sample size to take account of the clustered structure of the data - the residents were randomly sampled in buildings which were themselves randomly sampled. The quality of life of the individuals in one building was expected to correlate more strongly than individuals of similar characteristics in different buildings. In this situation, the contribution of each individual in statistical terms is reduced, and a larger sample is required. The target was to achieve full information for seven residents in each of 42 buildings, a total of 294 residents. To allow for missing data, I2 residents were randomly selected in each building from the list of long-stay residents. As the outcomes for staff could readily be assessed by questionnaire, all nursing and care staff in each participating building were surveyed. At the participating homes, consent was obtained from managers and residents (or where appropriate their relatives), following guidelines set by the local research ethics committees.

\section{The measures}

\section{The physical environment}

Reviews of the architectural and gerontological literature identified no single assessment tool which would capture all the relevant elements of building design. The most comprehensive was the Multiphasic Environmental Assessment Procedure, MEAP(Moos and Lemke I996), but it lacked coverage 
of some features, e.g. the sensory environment, and was devised for the somewhat different range of care settings in the United States. Several tools specifically for dementia care environments were found, including the Therapeutic Environment Screening Survey (TESS-NH) (Sloane et al. 2002), the Professional Environmental Assessment Procedure (PEAP) (Lawton et al. 2000), and Scales for the Assessment of Environments for the Confused Elderly (Bowie et al. I992; Tune and Bowie 2000).

It was therefore decided to use the reviews, together with care-industry standards and professional guidelines, to compile a comprehensive list of building features which had been suggested as important to building users. Individual features would be classified in a way that allowed for meaningful aggregation into a set of numeric scores. Statistical analysis could then test whether these aggregated scores were related to quality of life. Previous studies had identified different 'domains' of interest when assessing care buildings, including physical aspects such as availability of space, safety features and orientation cues, and extending to psychological attributes such as dignity, choice and individuality (Bowie et al. I992; Moos and Lemke 1996; Lawton 2001; Sloane et al. 2002).

To provide a comprehensive framework for the present study, io resident domains were chosen plus another that related to staff facilities. The Io resident domains cluster into three groups: universal requirements for older people living in residential settings (privacy, the ability to personalise their surroundings, choice and control, and connection with the wider community); physical requirements (safety and health, support for physical frailties, and comfort); and cognitive requirements (support for cognitive frailties, awareness of the outside world, and a domestic rather than institutional environment, which is referred to as 'normalness and authenticity'). Just over 300 individual features were identified from the literature, from industry guidelines and from pilot visits to care buildings, and these were each allocated to the relevant domain. Individual features were also cross-classified according to the architectural element within the building where they appeared, giving a two-way structure. The resulting matrix is known as the Sheffield Care Environment Assessment Matrix, SCEAM, and is shown in outline in Figure I. Examples of items in each domain are given in Table $\mathrm{I}$.

The majority of the individual features could be assessed by direct observation using a structured checklist. Those which involved room dimensions, such as the amount of lounge space per resident, were formatted into a protocol for analysing the building plans. Each individual feature was scored as present (I) or absent (o) in a building, and for each domain these scores were summed and expressed as a percentage of the total number of items. For example, the domain privacy has 40 features, and a building that 


\begin{tabular}{|l|l|l|l|l|l|l|l|}
\hline \multirow{2}{*}{ DOMAIN } & \multicolumn{5}{|c|}{ ARCHITECTURAL ELEMENT } \\
\cline { 2 - 8 } & Location & $\begin{array}{c}\text { Outside } \\
\text { spaces }\end{array}$ & $\begin{array}{c}\text { Building form } \\
\text { and circulation } \\
\text { spaces }\end{array}$ & $\begin{array}{c}\text { Day } \\
\text { spaces }\end{array}$ & $\begin{array}{c}\text { Bathrooms } \\
\text { and toilets }\end{array}$ & $\begin{array}{c}\text { Private } \\
\text { rooms }\end{array}$ & $\begin{array}{c}\text { Staff } \\
\text { spaces }\end{array}$ \\
\hline $\begin{array}{c}\text { Residents: universal } \\
\text { Privacy }\end{array}$ & & & & & & & \\
\hline Personalisation & & & & & & & \\
\hline Choice and control & & & & & & & \\
\hline Community & & & & & & & \\
\hline $\begin{array}{c}\text { Residents: physical } \\
\text { Safety and health }\end{array}$ & & & & & & & \\
\hline Support for physical frailty & & & & & & & \\
\hline Comfort & & & & & & & \\
\hline $\begin{array}{c}\text { Residents: cognitive } \\
\text { Support for cognitive frailty }\end{array}$ & & & & & & & \\
\hline Awareness of outside world & & & & & & & \\
\hline Normalness and authenticity & & & & & & & \\
\hline $\begin{array}{c}\text { Staff } \\
\text { Provision for staff }\end{array}$ & & & & & & & \\
\hline
\end{tabular}

Figure I. The structure of the Sheffield Care Environment Assessment Matrix (SCEAM).

met 30 of these would score 75 per cent. Each home is characterised by I I domain scores. The columns of the assessment matrix can be totalled to give scores for each architectural element.

Any differences between the building as designed and as observed in use were captured by the checklist and reflected in two alternative scores for each domain. For example, if the building included a shower room but it was used for storage and therefore unavailable for its intended purpose, the feature 'choice of bath or shower' in the 'choice/control' domain would score ' $\mathrm{I}$ ' for design but 'o' for use. In the present study, the scores for actual use were of most interest because they reflected the dayto-day experience of the users. The process of developing SCEAM gave it high face and content validity. Many of the binary factual items had shown perfect inter-rater reliability when used in similar settings (e.g. Sloane et al. 2002). Subjective assessments of temperature, air quality, light level and sound level were validated against objective measurements.

\section{The residents}

It was important to use achievable sources of information on the quality of life of all randomly selected residents, regardless of their cognitive or other frailties. The two sources that previous studies have shown to be effective are researcher observation and information from a proxy such as a spouse or formal care-giver (McKee, Houston and Barnes 2002). Observation of behaviour offers insights into internal states (Kitwood and Bredin 1992), 
T A B L E I. Example items from the Sheffield Care Environment Assessment Matrix

\begin{tabular}{|c|c|c|}
\hline Domain & $\mathrm{N}$ & Examples of items \\
\hline Privacy & 40 & $\begin{array}{l}\text { No resident bedrooms passed by outsiders (e.g. people visiting manager, } \\
\text { attending meetings). Bathroom/wc fittings not visible from corridor } \\
\text { when door open. Bedroom doors lockable from inside. }\end{array}$ \\
\hline Personalisation & 20 & $\begin{array}{l}\text { Shelving for personal items in dayroom. Emergency call points in } \\
\text { bedroom allow for different room layouts. Space to personalise } \\
\text { approaches to bedrooms (e.g. doors in alcoves). }\end{array}$ \\
\hline Choice and control & 25 & $\begin{array}{l}\text { Free access to garden/outside spaces. Choice of bath or shower. } \\
\text { Resident control of bedroom heating. }\end{array}$ \\
\hline Community & 20 & $\begin{array}{l}\text { On public transport route. Local services within } \frac{1}{4} \text { mile. Space for } \\
\text { family gatherings e.g. small lounge, kitchenette. }\end{array}$ \\
\hline Safety and health & 50 & $\begin{array}{l}\text { Garden/outdoor spaces have safeguards against wandering. Whole } \\
\text { dayroom visible from threshold. No unprotected heater or exposed } \\
\text { pipes in bathroom. }\end{array}$ \\
\hline $\begin{array}{l}\text { Support for } \\
\text { physical frailty }\end{array}$ & 47 & $\begin{array}{l}\text { All outside spaces accessible without steps. No bedroom more than } \\
\text { I5 m walk from dayroom (with lift journey if necessary). Shower } \\
\text { facilities for wheelchair users. }\end{array}$ \\
\hline Comfort & 24 & $\begin{array}{l}\text { Observed temperature satisfactory. Observed light level satisfactory. } \\
\text { Observed air quality satisfactory. }\end{array}$ \\
\hline $\begin{array}{l}\text { Support for } \\
\text { cognitive frailty }\end{array}$ & 27 & $\begin{array}{l}\text { Direction of main public spaces clear from all bedroom thresholds. } \\
\text { Bedroom doors recognisable by building element (e.g. staircase, } \\
\text { window, recess). Ensuite wc visible from bed. }\end{array}$ \\
\hline $\begin{array}{l}\text { Awareness of } \\
\text { outside world }\end{array}$ & 28 & $\begin{array}{l}\text { Weather-protected seating outside entrance. Corridors have view } \\
\text { of outside or internal courtyard. Spatial variation in temperature } \\
\text { within living unit. }\end{array}$ \\
\hline $\begin{array}{l}\text { Normalness and } \\
\text { authenticity }\end{array}$ & 30 & $\begin{array}{l}\text { No intrusive safety/security devices. Domestic décor in bathrooms } \\
\text { and wcs. Variety of natural materials. }\end{array}$ \\
\hline Provision for staff & 7 & $\begin{array}{l}\text { Separate changing room. Smoke-free area for eating separately from } \\
\text { residents. Common room with comfortable chairs. }\end{array}$ \\
\hline
\end{tabular}

Note: $\mathrm{N}$ is number of items.

and measures the extent to which the environment promotes general activity and social behaviour, and decreases disturbing behaviour (Lawton 200I). The external signs of emotional states offer a measure of the environment's success in increasing positive feelings and decreasing negative feelings (Lawton 1994).

\section{Observation by researchers}

'Dementia Care Mapping' (Kitwood and Bredin r992) is a technique and coding structure devised to study in detail the day-to-day experience of people with dementia. An observation period is divided into short time intervals, during which the person's activity is recorded using an A-Z coding framework, e.g. $\mathrm{N}$ for sleeping or dozing, $\mathrm{F}$ for eating or drinking, and $\mathrm{P}$ for receiving personal care. The person's apparent well-being or ill-being is also scored at each time on a six-point scale. ${ }^{1}$ There is detailed guidance on each combination of codes: e.g. ' $\mathrm{P}+3$ ' indicates 'receiving 
practical, physical or personal care, with sustained and positive interaction, such as being pleasantly helped to get dressed, or having an arthritic joint gently eased'. In this study, observations were made every I5 minutes during two-hour periods of the morning and afternoon. The activity codes were used to calculate the proportion of time the resident was involved in activity of any kind. A mean well-being/ill-being score was calculated for each resident over all observed intervals.

\section{Proxy information from care-workers}

The care-worker who knew the resident best was asked to complete a questionnaire on the resident's health and well-being. The CAPE Behaviour Rating Scale (CAPE-BRS) (Pattie and Gilleard I979) was used to establish level of dependency: it includes items on physical, cognitive and social functioning. The 20-item Pleasant Events Schedule-AD (PES-AD) (Logsdon and Teri 1997) measured the resident's participation in enjoyable activity: it takes into account both the frequency and apparent enjoyment of activities. The Affect Rating Scale (ARS) (Lawton 1994) produces two measures of outward signs of emotion: positive emotion (pleasure, interest and contentment), and negative emotion (anger, anxiety and depression). No suitable scale was found to assess the individual resident's ability to choose and control his or her immediate environment, and a I4-item scale for this purpose was devised. It covers freedom of movement around and outside the home (e.g. whether the resident used the garden unaccompanied by staff), whether the resident could control the heating, lighting and ventilation in their own room, and whether the resident chose their own bedroom furniture and decor. It was completed by the proxy care-worker and found to have good internal consistency (Cronbach's alpha 0.77).

\section{Other information on residents}

Managers provided information on all long-stay residents including date of birth, gender and length of residence. They were asked to give binary indications (good/poor) on a number of dimensions of dependency: communication (able to indicate needs and understand simple verbal directions); orientation (able to find way around, recognise and name people seen regularly); mobility (able to get around independently, using stick if needed); emotion (generally cheerful with positive outlook), and socialisation (establishes good relationships with others).

If the resident's cognitive or physical frailties did not preclude it, and the resident consented, structured interviews were conducted in private, usually in the resident's bedroom. Large print cue-cards were used to assist communication if required. Interviews included a short measure of cognitive 
function: the CAPE Information-Orientation Scale (CAPE-IO) (Pattie and Gilleard I979) and the Philadephia Geriatric Centre Morale Scale (PGCMS) (Lawton I975), which is frequently used to assess the morale of frail older people.

\section{The staff}

Questionnaires were sent to all nursing and care staff, covering job title, age, sex, hours per week, length of time in current job and in similar jobs, professional qualifications, and in-service training courses. The questionnaires contained two measures of job-related morale. The job satisfaction subscale of the Work and Life Attitudes Survey (WLAS) (Warr, Cook and Wall I979) is a broad assessment covering autonomy and responsibility, relationships with managers and co-workers, job security and opportunities for promotion. The Nursing Stress Scale (NSS) (Gray-Toft and Anderson I98I) has sub-scales that measure aspects of stress related to professional caregiving (death and dying, inadequate preparation, and lack of support). There was no suitable scale to assess staff satisfaction with the environment in the specific care setting, and a I6-item scale was therefore devised. This covered facilities for staff, features that facilitate the care of frail residents, and the internal environment (temperature, lighting, ventilation, noise and air quality). It was found to have good internal consistency (Cronbach's alpha 0.76 ). A reminder was sent to staff who did not return either the staff or proxy questionnaires within three weeks.

\section{Statistical methods}

In view of the clustered structure of the data, namely, individuals being sampled within buildings, the data were analysed using multi-level regression methods (Goldstein I995). This enabled the effect of building variables and resident or staff variables to be estimated correctly, and was carried out using $M L w i \mathcal{N}$ software (Rasbash et al. 200o). Ordinary regression methods would have under-estimated the confidence intervals and could have incorrectly shown associations to be significant. The models used the SCEAM domain variables as predictors, and the resident quality of life and staff morale variables as outcomes.

Outcomes with approximately normal distributions were modelled using the multi-level equivalent of linear regression. For residents, these were: proportion of time active (observation) and control over the environment (proxy). For staff, they were job satisfaction, job stress, and satisfaction with the environment. Residual plots were used to check the model assumptions of linearity, normality and constant variance, and to examine 
the effect of outlying values. Other outcomes had highly peaked or skewed distributions which could not be normalised by any of the common transformations. They were converted to binary variables, before modelling with the multi-level equivalent of logistic regression. These all related to resident outcomes and comprised apparent well-being/ill-being (observation), which was recoded as presence or absence of ill-being, and three proxy outcomes which were recoded using an approximate median split: enjoyment of pleasant activities, positive emotion, and negative emotion. ${ }^{2}$

Potential confounding variables were controlled for in all models, and were chosen principally on theoretical grounds. The size of the building (number of beds) was included as it had been used to stratify the random sample, and was strongly related to the type and ownership of the home. The principal characteristics of residents (age, gender and dependency) and of staff (age, job type and hours worked per week) were included in the appropriate models since they were expected to associate with both the care building and with quality of life. It was also thought essential to include a measure of the care-culture of the home. We had no prior knowledge to aid selection of the most appropriate variable: there were four candidate variables with strong inter-correlations (proportion of care staff qualified, proportion of care staff with in-service training, number of staff hours per resident per week, and the staff's median length of service). Of these variables, exploratory modelling showed that the proportion of care staff with in-service training contributed most to the models and it was therefore chosen as the variable to adjust for culture. For each model, individuals were excluded from the analysis if data on the quality of life outcome measure or any of the confounding variables were missing.

\section{Results}

\section{Recruitment and response}

Of the I30 care homes in the study area, Io6 were approached before the desired number was recruited. Nine of those approached had gone out of business, were being sold or had too few long-stay residents. Of the remainder, 59 declined to take part or failed to provide the necessary information, which included architectural plans of the building. The non-participants were predominantly in the small, private residential group (36 small, I2 medium, I large). The recruited sample comprised 38 homes, of which I I were small, I4 medium and I3 large. There were I,373 long-stay residents in these homes, and 452 were randomly selected for the study. There were I,o66 nursing and care staff in the selected homes. Figure 2 shows the flow of participants through the study. The response rate to the proxy questionnaires was 84 per cent, and as between the residents with and without 
Staff

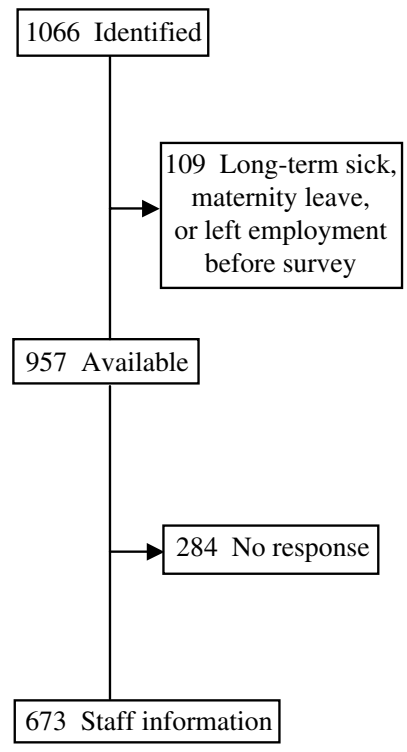

\section{Residents}

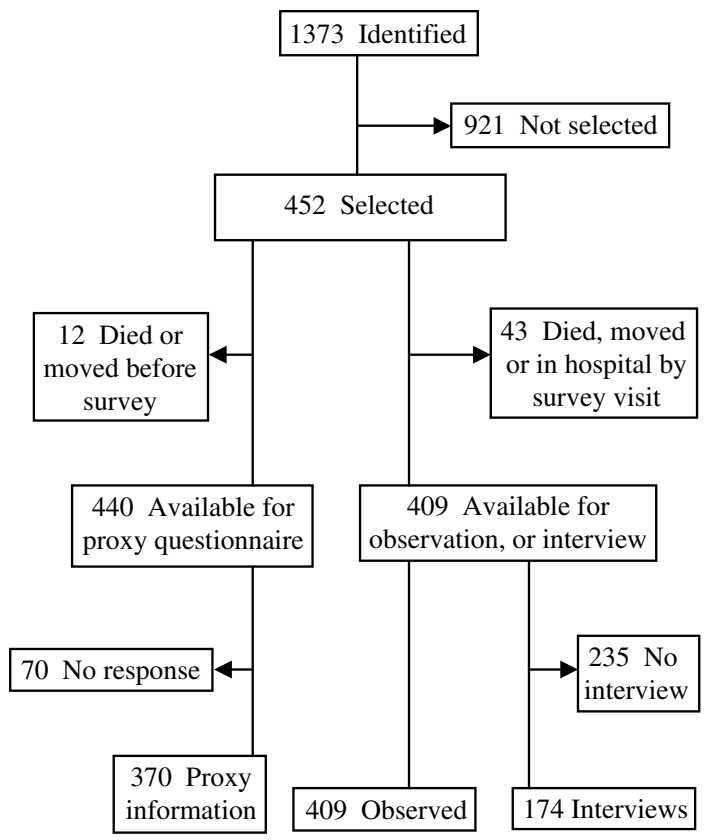

Figure 2. Flow of participants through the study.

proxy information, there were no differences in age, gender, length of stay, or dependency as assessed by the manager. Observations of quality of life were achieved for all available residents, and interviews were achieved with 43 per cent. The response rate to the staff questionnaire was 70 per cent.

\section{Descriptions of the buildings, residents and staff}

Table 2 summarises the building characteristics and SCEAM domain 'use' scores for the three types of home. There were substantial differences between the median domain scores for the three groups, and individual buildings also differed widely within each group. Small private homes had relatively high scores for choice/control, comfort, and the three cognitive domains, but their staff provision was low. Medium residential homes built by the local authority had relatively high personalisation and community scores. Large nursing homes had relatively high safety/health scores and low scores for personalisation and for the three cognitive domains.

Table 3 shows the residents' characteristics and quality of life scores: the latter were consistently lower for the large nursing homes than for the small and medium (predominantly residential care) homes. For example, 
T A B L E 2. Building characteristics and domain scores

\begin{tabular}{|c|c|c|c|}
\hline \multirow[b]{2}{*}{ Characteristic } & \multicolumn{3}{|c|}{ Size of homes } \\
\hline & $\begin{array}{c}\text { Small } \\
\text { Number }(\%)\end{array}$ & $\begin{array}{c}\text { Medium } \\
\text { Number }(\%)\end{array}$ & $\begin{array}{c}\text { Large } \\
\text { Number }(\%)\end{array}$ \\
\hline $\begin{array}{l}\text { Number of beds at each home } \\
\text { Number of homes }\end{array}$ & $\begin{array}{r}<3 \text { I } \\
\text { II }\end{array}$ & $\begin{array}{l}3{ }^{\mathrm{I}-40} \\
\mathrm{I} 4\end{array}$ & $\begin{array}{l}4 \mathrm{I}+ \\
\mathrm{I} 3\end{array}$ \\
\hline $\begin{array}{l}\text { Type of home: } \\
\text { Residential } \\
\text { Nursing } \\
\text { Dual }\end{array}$ & $\begin{array}{l}9(82) \\
2(18) \\
o(0)\end{array}$ & $\begin{array}{l}\text { I4 (IOO) } \\
\text { o (o) } \\
\mathrm{o}(\mathrm{o})\end{array}$ & $\begin{array}{l}\text { o (o) } \\
\text { Io }(77) \\
3(23)\end{array}$ \\
\hline $\begin{array}{l}\text { Ownership: } \\
\text { Private } \\
\text { Local authority } \\
\text { Voluntary association/trust }\end{array}$ & $\begin{array}{l}7(64) \\
0(0) \\
4(36)\end{array}$ & $\begin{array}{l}0(0) \\
7(50) \\
7(50)\end{array}$ & $\begin{array}{l}\text { I2 }(92) \\
\mathrm{O}(\mathrm{o}) \\
\mathrm{I}(8)\end{array}$ \\
\hline $\begin{array}{l}\text { Original use: } \\
\text { Conversion } \\
\text { Purpose-built }\end{array}$ & $\begin{array}{l}7(64) \\
4(36)\end{array}$ & $\begin{array}{l}\mathrm{o}(\mathrm{o}) \\
\text { I4 (IOO) }\end{array}$ & $\begin{array}{c}\text { I }(8) \\
\text { I2 }(92)\end{array}$ \\
\hline $\begin{array}{l}\text { Age: } \\
\text { Pre I945 } \\
\text { I945-1980 } \\
\text { Post I980 }\end{array}$ & $\begin{array}{l}7(64) \\
0(0) \\
4(36)\end{array}$ & $\begin{array}{l}\text { o (o) } \\
\text { I2 (86) } \\
2(\mathrm{I} 4)\end{array}$ & $\begin{array}{l}\text { I }(8) \\
\text { O (o) } \\
\text { I2 }(92)\end{array}$ \\
\hline $\begin{array}{l}\text { Location: } \\
\text { Inner suburb } \\
\text { Outer suburb } \\
\text { Rural }\end{array}$ & $\begin{array}{l}2(18) \\
6(55) \\
3(27)\end{array}$ & $\begin{array}{r}\text { IO (7I) } \\
2(\mathrm{I} 4) \\
2(\mathrm{I} 4)\end{array}$ & $\begin{array}{l}5(38) \\
2(\mathrm{I} 5) \\
6(46)\end{array}$ \\
\hline & Median (QI, Q3) & Median (QI, $\left.\mathrm{Q}_{3}\right)$ & Median $\left(\mathrm{Q}_{1}, \mathrm{Q}_{3}\right)$ \\
\hline $\begin{array}{l}\text { Number of long-stay residents: } \\
\text { Number of nursing/care staff: } \\
\text { Staff hours per resident per week: }\end{array}$ & $\begin{array}{l}20(\mathrm{I} 4,22) \\
\text { I5 (I3, I8) } \\
2 \mathrm{I}(\mathrm{I} 7,24)\end{array}$ & $\begin{array}{l}30(27,34) \\
\text { 2I (I } 19,24) \\
\text { I9 }(\mathrm{I} 7,24)\end{array}$ & $\begin{array}{l}54(43,69) \\
33(31,42) \\
25(20,28)\end{array}$ \\
\hline $\begin{array}{l}\text { Domain score (building as used): } \\
\text { Privacy } \\
\text { Personalisation } \\
\text { Choice/control } \\
\text { Community } \\
\text { Safety/health } \\
\text { Physical support } \\
\text { Comfort } \\
\text { Cognitive support } \\
\text { Awareness } \\
\text { Normalness } \\
\text { Staff }\end{array}$ & $\begin{array}{l}63(54,7 \mathrm{I}) \\
33(2 \mathrm{O}, 43) \\
58(40,6 \mathrm{o}) \\
60(5 \mathrm{O}, 65) \\
66(6 \mathrm{o}, 7 \mathrm{I}) \\
50(4 \mathrm{I}, 54) \\
83(75,88) \\
35(30,4 \mathrm{I}) \\
39(3 \mathrm{O}, 55) \\
72(62,8 \mathrm{o}) \\
43(29,57)\end{array}$ & $\begin{array}{l}5^{8}(53,64) \\
4^{\mathrm{I}}(33,5 \mathrm{O}) \\
49(46,57) \\
75(65,8 \mathrm{o}) \\
65(58,7 \mathrm{I}) \\
54(5 \mathrm{O}, 62) \\
7 \mathrm{I}(66,83) \\
27(20,3 \mathrm{I}) \\
3^{8}(33,48) \\
4^{8}(38,55) \\
7 \mathrm{I}(57,89)\end{array}$ & $\begin{array}{l}63(54,69) \\
\text { I5 (II } 25) \\
34(25,42) \\
58(55,63) \\
79(72,84) \\
57(49,62) \\
7 \mathrm{I}(64,75) \\
24(\mathrm{I} 9,27) \\
30(27,37) \\
45(42,5 \mathrm{I}) \\
7 \mathrm{I}(64,86)\end{array}$ \\
\hline
\end{tabular}

Note: QI, Q3 are the lower and upper quartile figures.

$3^{8}$ per cent of the residents in the small homes showed overall well-being, compared with 33 per cent in the medium-sized homes and I3 per cent in the large homes. The proportion of the available time that residents spent engaged in any activity was highest $(46 \%)$ in the medium-size homes, and 
T A в L E 3. Resident characteristics and quality of life outcomes

\begin{tabular}{|c|c|c|c|c|c|}
\hline \multirow[b]{2}{*}{ Characteristic } & \multirow[b]{2}{*}{$\begin{array}{l}\text { Sample } \\
\text { size }\end{array}$} & \multirow[b]{2}{*}{ Category } & \multicolumn{3}{|c|}{ Size of homes } \\
\hline & & & $\begin{array}{c}\text { Small } \\
\text { Number }(\%)\end{array}$ & $\begin{array}{c}\text { Medium } \\
\text { Number }(\%)\end{array}$ & $\begin{array}{c}\text { Large } \\
\text { Number }(\%)\end{array}$ \\
\hline $\begin{array}{l}\text { Number of selected } \\
\text { residents }\end{array}$ & & & $\mathrm{I} 28$ & I68 & I56 \\
\hline Gender & $45^{2}$ & $\begin{array}{l}\text { Female } \\
\text { Male }\end{array}$ & $\begin{array}{l}\text { Iog }(85) \\
\text { I9 (I5) }\end{array}$ & $\begin{array}{r}\text { I } 28(76) \\
40(24)\end{array}$ & $\begin{array}{l}\text { III }(7 \mathrm{I}) \\
45(29)\end{array}$ \\
\hline \multicolumn{6}{|l|}{ Quality of life scores } \\
\hline Well-being/ill-being & 388 & $\begin{array}{l}\text { Well-being } \\
\text { Neutral } \\
\text { Ill-being }\end{array}$ & $\begin{array}{l}36(38) \\
43(45) \\
\text { I7 (I8) }\end{array}$ & $\begin{array}{l}5 \mathrm{I}(33) \\
76(49) \\
28(\mathrm{I} 8)\end{array}$ & $\begin{array}{l}\text { I8 (I3) } \\
62(45) \\
57(42)\end{array}$ \\
\hline $\begin{array}{l}\text { Enjoyment of } \\
\text { activities }\end{array}$ & 357 & $\begin{array}{l}\text { High } \\
\text { Low }\end{array}$ & $\begin{array}{l}65(62) \\
40\left(3^{8}\right)\end{array}$ & $\begin{array}{l}62(5 \mathrm{I}) \\
59(49)\end{array}$ & $\begin{array}{l}5 \mathrm{I}(39) \\
8 \mathrm{o}(6 \mathrm{I})\end{array}$ \\
\hline Positive emotion & 357 & $\begin{array}{l}\text { High } \\
\text { Low }\end{array}$ & $\begin{array}{l}6 \text { I }(60) \\
4 \mathrm{I}(40)\end{array}$ & $\begin{array}{l}73\left(5^{8}\right) \\
52\left(4^{2}\right)\end{array}$ & $\begin{array}{l}66(5 \mathrm{I}) \\
64(49)\end{array}$ \\
\hline \multirow[t]{2}{*}{ Negative emotion } & 356 & $\begin{array}{l}\text { Low } \\
\text { High }\end{array}$ & $\begin{array}{l}6 \text { I }(6 o) \\
4 \mathrm{I}(40)\end{array}$ & $\begin{array}{l}66(53) \\
58(47)\end{array}$ & $\begin{array}{l}55(42) \\
75(58)\end{array}$ \\
\hline & & & Median (QI, Q3) & Median (Q1, Q3) & Median $\left(\mathrm{Q}_{\mathrm{I}}, \mathrm{Q}_{3}\right)$ \\
\hline Age & $45^{\mathrm{I}}$ & & $86\left(8 \mathrm{I}, 9^{2}\right)$ & $85(80,90)$ & $8_{3}(77,88)$ \\
\hline Dependency ${ }^{1}$ & 368 & & I2 $(9, \mathrm{I} 7)$ & I $4(9$, I8) & I9 $(15,23)$ \\
\hline Months of stay & 436 & & I9 $(7,46)$ & $24(\mathrm{IO}, 47)$ & $20(9,49)$ \\
\hline \multicolumn{6}{|l|}{ Quality of life scores } \\
\hline $\begin{array}{l}\text { Per cent of time } \\
\text { active }^{2}\end{array}$ & 390 & & $3^{8}(\mathrm{r} 9,57)$ & $4^{6}(3 \mathrm{I}, 63)$ & $28\left(\mathrm{I} 3,4^{8}\right)$ \\
\hline Choice/control $^{3}$ & 369 & & $5(3,7)$ & $5(3,9)$ & $2(\mathrm{I}, 4)$ \\
\hline $\begin{array}{l}\text { Self-reported } \\
\text { morale }^{4}\end{array}$ & I74 & & Io $(7$, I 3$)$ & Io $(7, \mathrm{I} 2)$ & $9(5,13)$ \\
\hline
\end{tabular}

Notes: I. Range from 'o' independent to ' 36 ' maximum dependency. 2. Range from 'o' lowest activity to 'Ioo' highest activity. 3 . Choice/control over environment: range from ' 0 ' least control to 'I4' most control. 4. Range from 'o' lowest morale to ' 17 ' highest morale. QI, $Q_{3}$ are the lower and upper quartile figures.

lower in both the small $(38 \%)$ and large $(28 \%)$ homes. Self-reported morale scores differed little between the residents of the residential homes and the few in nursing homes who were able to complete the interview.

Table 4 shows the characteristics of the nursing and care staff and their morale scores. Medium-size homes had the highest proportion of staff with in-service training. In large homes the staff turnover was twice as rapid as in the other two groups. Staff in large homes worked longer hours per week. Job satisfaction was lowest in the large homes, with no substantial difference between groups on job stress or satisfaction with the environment. The descriptive results presented in Tables $2-4$ confirm that buildings differed considerably in the characteristics of their residents and staff as well as in their physical environment. The quality of life scores tended 
T A B L E 4. Staff characteristics and quality of life outcomes

\begin{tabular}{|c|c|c|c|c|c|}
\hline \multirow[b]{2}{*}{ Characteristic } & \multirow[b]{2}{*}{$\begin{array}{l}\text { Sample } \\
\text { size }\end{array}$} & \multirow[b]{2}{*}{ Category } & \multicolumn{3}{|c|}{ Size of homes } \\
\hline & & & $\begin{array}{c}\text { Small } \\
\text { Number (\%) }\end{array}$ & $\begin{array}{c}\text { Medium } \\
\text { Number (\%) }\end{array}$ & $\begin{array}{c}\text { Large } \\
\text { Number }(\%)\end{array}$ \\
\hline $\begin{array}{l}\text { Number of } \\
\text { surveyed staff }\end{array}$ & & & I7I & 293 & 493 \\
\hline \multirow[t]{2}{*}{ Gender } & 668 & Female & I45 (96) & I87 (9I) & $279(90)$ \\
\hline & & Male & $6(4)$ & I9 (9) & $3^{2}(\mathrm{IO})$ \\
\hline \multirow[t]{3}{*}{ Job category } & 672 & Senior ${ }^{4}$ & I8 (I2) & 39 (I9) & I8 (6) \\
\hline & & Nursing & Io $(7)$ & $\mathrm{o}(\mathrm{o})$ & $87(28)$ \\
\hline & & Care & I23 (8I) & I67 (8I) & $2 \mathrm{IO}(67)$ \\
\hline \multirow{2}{*}{$\begin{array}{l}\text { Relevant } \\
\text { qualification }\end{array}$} & 670 & Yes & $62(4 \mathrm{I})$ & $4 \mathrm{I}(20)$ & I48 (47) \\
\hline & & No & $89(59)$ & I65 (80) & I65 (53) \\
\hline \multirow[t]{3}{*}{ In-service training } & 670 & Yes & I2O (79) & I96 (95) & $235(75)$ \\
\hline & & No & $3^{\mathrm{I}}(2 \mathrm{I})$ & IO (5) & $78(25)$ \\
\hline & & & $\operatorname{Median}\left(\mathrm{Q}_{1}, \mathrm{Q}_{3}\right)$ & Median (Q1, Q3) & Median (Q1, Q3) \\
\hline Age (years) & 662 & & $4^{2}(29,53)$ & $3^{8}\left(3^{1}, 5^{0}\right)$ & $39(27,48)$ \\
\hline Months of service & 665 & & $4 \mathrm{I}(\mathrm{I} 8,72)$ & $43(18,96)$ & $20\left(8,4^{6}\right)$ \\
\hline $\begin{array}{l}\text { Hours worked } \\
\text { per week }\end{array}$ & 660 & & $30(2 \mathrm{I}, 35)$ & $30(25,35)$ & $3^{6}(32,43)$ \\
\hline \multicolumn{6}{|l|}{ Quality of life scores } \\
\hline Job satisfaction ${ }^{1}$ & 666 & & $8 \mathrm{I}(70,88)$ & $79(68,87)$ & $72(6 \mathrm{I}, 79)$ \\
\hline Job stress ${ }^{2}$ & 657 & & I3 $(8$, I7) & I4 (Io, I9) & I5 $(\mathrm{II}, 20)$ \\
\hline $\begin{array}{l}\text { Environmental } \\
\text { satisfaction }^{3}\end{array}$ & 673 & & II $(9$, I 3$)$ & $9(7, \mathrm{I} 2)$ & Io $(8$, I3) \\
\hline
\end{tabular}

Notes: I. Range from 'I5' least satisfaction to ' 105 ' most satisfaction. 2. Range from 'o' for 'least stress' to '39' for 'most stress'. 3. Range from 'o' for 'least satisfaction' to ' $\mathrm{I} 6$ ' for 'most satisfaction'. 4. 'Senior' includes deputy and assistant managers, team leaders and charge nurses/sisters.

to be highest in medium-size residential homes: these buildings were characterised by high scores for personalisation and community, but their resident and staff groups were also distinct, with low levels of dependency among residents and high levels of in-service training among staff.

\section{Associations between the physical environment and quality of life}

Table 5 shows the estimated associations between the building domain variables and quality of life outcomes that were significant at the five per cent level after adjustment for potential confounders. Of the two alternative scores for each building domain, 'use' scores were found to be more strongly associated with outcomes than 'design' scores: the former are shown in Table 5. For residents, the domain choice/control was related to well-being, community was related to level of activity, physical support was related to control over the environment, and cognitive support was related to positive emotion. These were all positive associations; e.g. a one-point 
T A B L E 5. Overall associations between building domain scores and quality of life

\begin{tabular}{|c|c|c|c|c|c|}
\hline \multirow[b]{2}{*}{ Building domain } & \multirow[b]{2}{*}{ Quality of life outcome } & \multicolumn{2}{|c|}{ Change in $\mathrm{QoL}^{1}$} & \multirow[b]{2}{*}{$p$} & \multirow[b]{2}{*}{$\mathrm{N}$} \\
\hline & & Estimate & $95 \%$ c.i. & & \\
\hline Privacy & None & & & & \\
\hline Personalisation & + Staff job satisfaction ${ }^{2}$ & +0.18 & $+0.01,+0.36$ & $0.04 \mathrm{I}$ & 636 \\
\hline Choice/control & + Resident wellbeing ${ }^{3}$ & +0.03 & $+0.00,+0.06$ & 0.042 & 327 \\
\hline Community & + Resident per cent of time active $e^{2}$ & +0.43 & $+0.18,+o .68$ & $<0.001$ & 329 \\
\hline Safety/health & $\begin{array}{l}\text { - Resident enjoyment activities }{ }^{3} \\
\text { - Resident environmental control }\end{array}$ & $\begin{array}{l}-0.04 \\
-0.06\end{array}$ & $\begin{array}{l}-0.08,-0.00 \\
-0.10,-0.03\end{array}$ & $\begin{array}{l}0.033 \\
0.00 I\end{array}$ & $\begin{array}{l}354 \\
367\end{array}$ \\
\hline $\begin{array}{l}\text { Physical support } \\
\text { Comfort }\end{array}$ & $\begin{array}{l}+ \text { Resident environmental control } \\
\text { None }\end{array}$ & + o.Io & $+0.06,+0.15$ & $<0.001$ & 367 \\
\hline $\begin{array}{l}\text { Cognitive support } \\
\text { Awareness }\end{array}$ & $\begin{array}{l}+ \text { Resident positive emotion }{ }^{3} \\
\text { None }\end{array}$ & +0.03 & $+0.00,+0.06$ & $0.04 \mathrm{I}$ & 355 \\
\hline Normalness & $\begin{array}{l}\text { - Staff job stress } \\
+ \text { Staff environmental satisfaction }\end{array}$ & $\begin{array}{l}-0.06 \\
+0.07\end{array}$ & $\begin{array}{l}-0 . \mathrm{IO},-\mathrm{O} . \mathrm{OI} \\
+0.03,+\mathrm{o.II}\end{array}$ & $\begin{array}{l}0.018 \\
0.001\end{array}$ & $\begin{array}{l}636 \\
636\end{array}$ \\
\hline Staff provision & None & & & & \\
\hline
\end{tabular}

Notes: + raises outcome score. - decreases outcome score. c.i. confidence interval. I. Change associated with one-point increase in domain score. 2. For continuous outcomes, value tabulated is the estimated difference in quality of life score. 3. For binary outcomes, value tabulated is the estimated difference in the log odds of a high quality of life. $4 . p$ value derived by referring change in fit of model $-2 \log$ likelihood to $\chi^{2}$ distribution (I degree of freedom).

increase in the community score was associated with an increase of 0.43 in the percentage of the resident's time that they were active. There were also two negative associations: higher scores for the domain safety/health were related to lower scores for enjoyment of activities and for environmental control. The outcome 'self-reported morale' was not modelled since many residents had missing data, particularly among those in nursing homes, and there was a strong bias towards the cognitively and physically fittest. Staff outcomes showed no association with staff provision in the building but had positive associations with the domains normalness/authenticity and personalisation. The domains privacy, comfort and awareness produced no significant associations in these analyses.

Several other building variables were checked for any association with quality of life, namely age, location, whether purpose-built, and the amount of space per resident (private bedroom space and share of communal space). Controlling for the same confounding variables, none made a significant contribution to any of the models. The size of the building, which was included in all models, made an independent contribution to only one measure of quality of life: an increase in size was associated with a reduction in the residents' control over the environment.

Resident dependency level as a moderator of environment/quality of life associations

Significant interactions in the models showed that in some cases the relationships between building domains and quality of life differed with the 
T А в L E 6. Associations between quality of life and domain scores for resident subgroups by the dependency level of the residents

\begin{tabular}{|c|c|c|c|}
\hline \multirow[b]{2}{*}{ Quality of life outcome } & \multicolumn{3}{|c|}{ Residents' dependency level } \\
\hline & Low & High & All \\
\hline Proportion of time active & Community $(+)$ & Physical support (+) & Community $(+)$ \\
\hline Well-being & Comfort $(+)$ & Choice/control (+) & Choice/control (+) \\
\hline Enjoyment of activities & Safety/health $(-)$ & None & Safety/health (-) \\
\hline Positive emotion & $\begin{array}{l}\text { Community }(-) \\
\text { Normalness }(+)\end{array}$ & None & Cognitive support $(+)$ \\
\hline Negative emotion & Community $(+)$ & None & None \\
\hline Environmental control & Physical support $(+)$ & $\begin{array}{l}\text { Personalisation }(+) \\
\text { Physical support }(+)\end{array}$ & $\begin{array}{l}\text { Physical support }(+) \\
\text { Safety }(-)\end{array}$ \\
\hline
\end{tabular}

Notes: $(+)$ higher values of domain variable associated with higher quality of life. $(-)$ higher values of domain variable associated with lower quality of life.

level of dependency of the resident. To investigate these differences, the residents were split into two subgroups based on the established low (score o-I2) and high (score I3-36) dependency categories of the CAPE BRS scale. Table 6 summarises the different associations in the two groups for each quality of life measure. For example, the proportion of time that was spent active was associated with the community domain for all residents and for the low dependency group, but among the high dependency group it was more related to physical support. The overall negative association between enjoyment of activities and the safety/health domain was seen in the low dependency but not the high dependency residents. The domains comfort and normalness/authenticity had positive associations with quality of life for the low dependency subgroup (respectively with well-being and positive emotion) but not among all residents.

\section{Discussion}

\section{Main findings}

Quality of life is a multi-dimensional construct which brings together diverse attributes such as physical health, psychological state, level of independence and social relationships (WHOQOL Group 1998). The measures chosen for the present study reflected this complexity, and the analysis has shown that different aspects of the built environment associated with different measures of the quality of life. Provision in the building design for choice and control, which includes access to various indoor and outdoor spaces and facilities, was associated with observed well-being. The extent to which the building was connected to the wider community, e.g. in 
its location and provision for visitors, was associated with the observed level of activity among residents. Support provided by the building for residents with physical frailties, including reduced mobility and sensory impairment, was related to the residents' ability to control their immediate environment. Support for cognitive frailties, such as sensory stimulation and ease of way-finding, was associated with outward signs of positive emotion. The only negative associations involved building features related to safety and health, which associated with lower scores for the residents' enjoyment of activities and control of the environment.

The importance of choice and control for the well-being of older people has long been established (e.g. Langer and Rodin 1976). The finding of a link between choice and control over the care home environment and observed well-being adds to our knowledge. The study has also reinforced the importance of adequate environmental support for older residents with cognitive, functional and sensory incapacity, as argued in Lawton's environmental docility hypothesis (Lawton I982). In homes with design features that offered the most compensation for physical and sensory frailties, the residents displayed the greatest control over their immediate environment, and where there was greater compensation for cognitive incapacity, residents displayed more positive affect. Much research evidence points to a link between activity levels and well-being in older people (e.g. McKee, Houston and Barnes 2002), and our findings demonstrate higher activity levels in care homes which offer their residents continued social integration and the maintenance of existing social networks through design features. The evidence from this study therefore suggests that attention to several aspects of building design is essential if global quality of life is to be maximised.

\section{Safety versus well-being}

Care homes are understandably subject to many health and safety regulations. They must protect their frail residents as well as function as work places and settings for medical interventions. The perceived pressures from relatives and fear of litigation may foster a risk-averse environment, however, which our findings associate with a measurable diminution in some aspects of quality of life. An example is that very few homes provide residents with ready access to garden spaces, for fear of the harm that might occur if they wander from the premises or fall. Another example is that many fire-protection devices that keep bedroom doors closed exert considerable force, are difficult to counteract, and therefore impede the free movement of residents with limited mobility. More innovative solutions to these conflicts between safety and freedom are already available and 
others are being developed. The National Service Framework for Older People (Department of Health 200I $b$ ) endorses the notion that older people should be able to 'determine the level of personal risk they are prepared to take when making decisions about their own health and circumstances', but it appears that the directive has as yet had little impact on the careculture of residential settings.

\section{Findings on different building users}

In designing care buildings, a balance has to be struck between the sometimes conflicting needs of different building users. A single building typically houses residents with a wide spectrum of dependency, and the subgroup analyses confirmed that different building characteristics promote the quality of life of people at different points on this spectrum. While the level of activity associated with community provision among low dependency residents, a more influential building dimension for the high dependency group was support for physical frailty. The negative association between safety/health features and quality of life was significant only among the low dependency residents. These findings underline the challenge involved in developing inclusive designs that cater for the full range of cognitive and physical frailties. The needs of staff may also conflict with those of residents, e.g. staff may wish to keep residents under surveillance for their safety while residents desire more privacy (Morgan and Stewart 1999). It was interesting that we found staff morale to be associated not with better staff facilities but with a more personalised, less institutional environment for the residents.

\section{Methodological developments}

The study has developed a new tool for assessing care buildings from the viewpoint of building users. The SCEAM describes a building through a profile of scores which can be used for comparative assessments. The findings have shown that the SCEAM instrument summarises buildings in a way that is relevant to the residents' quality of life, and demonstrated the concurrent validity of the tool. This method of describing buildings revealed interesting findings, e.g. that environmental features that compensate for cognitive impairment were more prevalent in small residential homes than in the large nursing homes that specialise in dementia care. This arises from the more domestic and recognisable layout of small homes, and the varying environments of converted large old houses, compared with the long and relatively featureless corridors and uniform environments of purpose-built units. 
The SCEAM was devised for the full spectrum of UK residential and nursing care settings. By retaining items which had high or low prevalence in the study sample it has achieved a wider applicability. The tool has subsequently been piloted for research in related environments, such as hospital wards and sheltered housing, and found to need little adaptation. We would welcome its wider use in similar and related care or sheltered settings. A possible development of the SCEAM would be to weight the scoring of individual building features according to some measure of their relative importance, but the unweighted scoring preserves its applicability to diverse settings. The present study also used new tools for assessing residents' ability to control their environment and staff satisfaction with their working environment. These had good internal consistency and showed significant relationships with the built environment. ${ }^{3}$

The SCEAM has clear uses in the long-term care sector. Its administration does not require expertise in building design, and the largest buildings take around half-a-day to assess. It is based on many individual building features and can therefore identify precisely where performance could be improved. The SCEAM generates scores for both the way the building was designed and the way it is actually utilised: as expected, it was found that the latter scores associated more closely with the residents' quality of life. Any shortfall between design intentions and actual performance must be worth exploring by care providers. The SCEAM has also been used successfully to appraise proposed new developments from the architectural plans.

\section{Limitations of the present study}

The study was conducted during a period of considerable change in the British residential care sector, with smaller and older residential homes being particularly vulnerable to closure. This may have contributed to the greater difficulty we experienced in recruiting the small homes. The reasons given for refusal were principally an unwillingness to complete the initial paperwork and an inability to provide architectural plans of the building. In the recruited homes, less than one-half of the randomlyselected residents were able and willing to provide self-reports of their quality of life, with cognitive frailty being the most common reason for failure to achieve an interview. The residents who were interviewed were therefore the cognitively and physically fittest, and particularly in many EMI homes it was possible to complete the full interview with only one or two residents.

The indirect sources of information on the residents' quality of life were therefore most important, i.e. proxy information from the care-worker 
who knew the resident best, and observation by researchers. From the proxy we obtained information on the resident's participation in enjoyable activity (the PES-AD). In this population and with care-workers as proxy informants, the PES-AD score had a highly skewed distribution, with over 20 per cent of the residents scoring zero. For low-scoring individuals, the care-workers typically indicated that while several activities were carried out, they could not record them as being enjoyed - care-workers may not feel as qualified to judge affect as, for example, a spouse-carer. The observation method was based on Dementia Care Mapping, a technique devised to study the experience of people with dementia with a view to improving the care that they receive. It was found that the well-being/ ill-being score computed in Dementia Care Mapping had a very peaked distribution, with around 50 per cent of the residents scoring 'neutral': it was not therefore a very discriminating outcome measure.

\section{Conclusions and implications for policy and practice}

We have demonstrated cross-sectional relationships between the built environment of care homes for older people and the quality of life of the residents and the morale of the staff. Building features related to choice and control, community, physical support, normalness/authenticity, cognitive support, comfort and personalisation were all positively associated with different aspects of quality of life. There was evidence that the stringent safety and health requirements for these environments negatively affected the quality of life of the less dependent residents. A new tool for assessing the physical environment of residential and nursing care homes has been devised, and it has the potential for further research and practical applications. British government policy has recently moved away from the prescriptive regulation of existing care homes, and while this crosssectional study cannot prove cause and effect, the findings are a timely reminder of the importance of the physical environment. Older people who live in residential and nursing care settings necessarily spend most of their time within the boundaries of the home, which places an obligation on designers and care providers to maximise the residents' quality of life by close attention to the design features of the environment.

\section{Acknowledgements}

The Design in Caring Environments Study was funded by the UK Engineering and Physical Sciences Research Council through its EQUAL (Extending Quality of Life) programme (Grant GR/M/70025). The authors are very grateful for the assistance given by owners, managers, staff and residents of participating care homes and by Sheffield City Council. 


\section{NOTES}

I The scale is $-5,-3,-\mathrm{I},+\mathrm{I},+3,+5$, where ' -5 ' indicates severe ill-being, ' $+\mathrm{I}$ ' indicates fairly low involvement but no signs of ill-being (effectively the 'neutral' score), and ' +5 ' indicates very high enjoyment or involvement.

2 The association of each domain variable with quality of life was assessed by comparing the fit of the model $(-2 \log$ likelihood) when the variable was included or excluded, and referring this difference to the chi-squared distribution with one degree of freedom.

3 The authors would be pleased to provide further details of any of the measures and instruments described in this paper.

\section{References}

Barnes, S. 2002. The design of caring environments and the quality of life of older people. Ageing \& Society, 22, 775-89.

Bowie, P., Mountain, G. and Clayden, D. 1992. Assessing the environmental quality of longstay wards for the confused elderly. International fournal of Geriatric Psychiatry, 7, 95-I04.

Brawley, E. C. 200I. Environmental design for Alzheimer's disease: a quality of life issue. Aging and Mental Health, 5 (supplement I), S79-83.

Calkins, M. P. 200r. The physical and social environment of the person with Alzheimer's disease. Aging and Mental Health, 5 (supplement I), S74-8.

Department of Health 2001 $a$. Care Homes for Older People: National Minimum Standards. Stationery Office, London.

Department of Health 2001 $b$. National Service Framework for Older People. The Stationery Office, London, 27.

Duffy, M., Bailey, S., Beck, B. and Barker, D. G. I986. Preferences in nursing home design: a comparison of residents, administrators, and designers. Environment and Behaviour, $\mathbf{1 8}, 24^{6-57 .}$

Gilloran, A., Robertson, A., McGlew, T. and McKee, K. I995. Improving work satisfaction amongst nursing staff and quality of care for elderly patients with dementia: some policy implications. Ageing \& Society, I5, 375-91.

Goldstein, H. 1995. Multilevel Statistical Models. Arnold, London.

Gray-Toft, P. and Anderson, J. G. I98I. The 'Nursing Stress Scale': development of an instrument. Fournal of Behavioural Assessment, 3, II-23.

Higgs, P. F. D., MacDonald, L. D., MacDonald, J. S. and Ward, M. C. I998. Home from home: residents' opinions of nursing homes and long-stay wards. Age and Ageing, 27, I99-205.

Judd, S., Marshall, M. and Phippen, P. 1998. Design for Dementia. Hawker, London.

Kellaher, L. A. I986. Determinants of quality of life in residential settings for old people. In Judge, K. and Sinclair, I. (eds), Residential Care for Elderly People. Her Majesty's Stationery Office, London, 127-37.

Kitwood, T. and Bredin, K. I992. A new approach to the evaluation of dementia care. Fournal of Advances in Health and Nursing Care, I, 4I-60.

Langer, E. J. and Rodin, J. I976. The effects of choice and enhanced personal responsibility for the aged: a field experiment in an institutional setting. Fournal of Personality and Social Psychology, 34, I9 ${ }^{-}-8$.

Lawton, M. P. I975. The Philadelphia Geriatric Center Morale Scale: a revision. fournal of Gerontology, 30, 85-9.

Lawton, M. P. I982. Competence, environmental press, and the adaptation of older people. In Lawton, M. P., Windley, P. G. and Byerts, T. O. (eds), Aging and the Environment: Theoretical Approaches. Springer Publishing Company, New York, 33-59. 
Lawton, M. P. 1994. Quality of life in Alzheimer disease. Alzheimer Disease and Associated Disorders, 8 (supplement 3), I38-50.

Lawton, M. P. 200I. The physical environment of the person with Alzheimer's disease. Aging and Mental Health, 5 (supplement I), $\mathrm{S}_{5} 6-64$.

Lawton, M. P., Weisman, G., Sloane, P., Norris-Baker, G., Calkins, M. and Zimmerman, Z. I. 2000. A 'Professional Environmental Assessment Procedure' for special care units for elders with dementing illness and its relationship to the 'Therapeutic Environment Screening Schedule'. Alzheimer Disease and Associated Disorders, I4, 28-38.

Logsdon, R. G. and Teri, L. 1997. The Pleasant Events Schedule-AD: psychometric properties and relationship to depression and cognition in Alzheimer's disease patients. The Gerontologist, 37, 40-5.

McKee, K. J., Houston, D. M. and Barnes, S. 2002. Methods for assessing quality of life and well-being in frail older people. Psychology and Health, 1 7, 737-51.

Moos, R. and Lemke, S. I980. Assessing the physical and architectural features of sheltered care settings. Fournal of Gerontology, 35, 57 I-83.

Moos, R. H. and Lemke, S. 1996. Evaluating Residential Facilities. Sage, London.

Morgan, D. G. and Stewart, N. J. I999. The physical environment of Special Care Units: needs of residents with dementia from the perspective of staff and family caregivers. Qualitative Health Research, 9, $\mathrm{IO}^{-\mathrm{I} 8 .}$

Netten, A. I989. The effect of design of residential homes in creating dependency among confused elderly residents. International Fournal of Geriatric Psychiatry, 4, I43-53.

Netten, A. I993. A Positive Environment? Physical and Social Influences on People with Senile Dementia in Residential Care. Ashgate, Aldershot, Hampshire.

Pattie, A. H. and Gilleard, C. J. 1979. Manual of the Clifton Assessment Procedures for the Elderly. Hodder and Stoughton, Sevenoaks, Kent.

Pearson, A., Hocking, S., Mott, S. and Riggs, A. I993. Quality of care in nursing homes: from the resident's perspective. Fournal of Advanced Nursing, I8, 20-4.

Rasbash, J., Browne, W., Goldstein, H., Yang, M., et al. 2000. A User's Guide to MlwiN, second edition. Institute of Education, University of London, London.

Sloane, P. D., Mitchell, C. M., Weisman, G., Zimmerman, S., Long Foley, K. M., Lynn, M., Calkins, M., Lawton, M. P., Teresi, J., Grant, L., Lindeman, D. and Montgomery, R. 2002. The Therapeutic Environment Screening Survey for Nursing Homes (TESS-NH): an observational instrument for assessing the physical environment of institutional settings for persons with dementia. Journal of Gerontology: Social Sciences, ${ }_{57}$ B, S69-78.

Torrington, J. 1996. Care Homes for Older People: A Briefing and Design Guide. Spon, London.

Tune, P. and Bowie, P. 200o. The quality of residential and nursing-home care for people with dementia. Age and Ageing, 29, 325-8.

Warr, P., Cook, J. and Wall, T. I979. Scales for the measurement of some work attitudes and aspects of psychological well-being. Fournal of Occupational Psychology, 52, 129-48.

World Health Organisation Quality of Life Assessment (WHOQOL) Group I998. The World Health Organisation Quality of Life Assessment: development and general psychometric properties. Social Science and Medicine, 46, I569-85.

Accepted I April 2004

Address for correspondence:

Chris Parker, Sheffield Institute for Studies on Ageing,

University of Sheffield, Community Sciences Centre, Northern General Hospital, Sheffield $\mathrm{S}_{5} 7 \mathrm{AU}$, UK.

e-mail: c.parker@sheffield.ac.uk 